\title{
BRIEF
}

\section{Pass the SOAP: Shifting from SOAP to Consult Notes for Clinical Documentation in Pharmacy Students}

\author{
Courtney L. Bradley, PharmD, Karlie Wieder, PharmD, Shaina E. Schwartz, PharmD \\ High Point University, Fred Wilson School of Pharmacy, High Point, North Carolina \\ Corresponding Author: Courtney L. Bradley, High Point University, Fred Wilson School of Pharmacy, 833 Montlieu Ave., High \\ Point, NC 27268. Tel: (336) 841-9715. Email: cbradley@highpoint.edu
}

Submitted June 22, 2021; accepted November 12, 2021; ePublished December 2021

Objective. Clinical documentation is an important element of patient care that pharmacy students traditionally learn through Subjective-Objective-Assessment-Plan (SOAP) notes. In clinical practice, pharmacists often document more succinctly both in regard to length and time; utilizing formats such as consult notes. The objective of this study was to assess consult note assignments for third-year pharmacy students (P3).

Methods. Consult note assignments were implemented in a P3 skills laboratory course by converting SOAP notes to consult notes. The series began with an introduction and a practice consult note. Four graded notes were then completed throughout the semester with time allotted for writing decreasing throughout the semester. To assess the series, grades and estimated time for completion were collected for each graded note. A pre-post survey assessed student self-confidence in: 1) overall documentation, 2) specific elements of consult notes, and 3) concerns related to writing. Friedman's tests were utilized to compare grades and time. Wilcoxon Signed Rank tests were used to compare self-assessments.

Results. Median consult note grades were: $92 \%, 88 \%, 80 \%$, and $90 \%$ for each note. Median time for completion were: 75 minutes, 120 minutes, 60 minutes, and 60 minutes. Student self-confidence in writing consult notes significantly increased as did five of the six individual elements.

Conclusion. The consult note assignments allowed students to practice documenting patient care in a succinct format with consideration for time efficiency. Further work should evaluate best pedagogies for teaching documentation skills and assess the impact on performance during advanced pharmacy practice experiences.

Keywords: documentation, SOAP notes, consult notes, pharmacy education, pharmacy student

\section{INTRODUCTION}

It is essential for pharmacists to accurately and efficiently document clinical recommendations. Common forms of written communication include comprehensive Subjective, Objective, Assessment, Plan (SOAP) notes and abbreviated consult notes. ${ }^{1}$ The SOAP note format is typically an initial pedagogy as it requires clinical reasoning to develop treatment plans for an entire patient case. Consult notes are targeted and concise responses to a specific medication-related problem such as dosing consults. This format allows pharmacists to quickly and efficiently communicate recommendations to providers.

Documentation skills are introduced early in pharmacy curricula and often focus on SOAP notes to teach the Pharmacists' Patient Care Process. ${ }^{2,3}$ Although variable across the academy, SOAP notes can include 85 potential elements such as specific items for subjective, objective, assessment, and plan. ${ }^{4}$ Students may learn to become proficient in documentation over time, but the speed at which SOAP notes can be completed is limited by their comprehensive nature.

Currently, preferred documentation formats utilized in patient care settings, such as hospitals, are abbreviated notes with only final recommendations. ${ }^{5,6,7}$ Although their effectiveness in communication is evident, ${ }^{8}$ students must learn to accommodate different providers' preferences for capturing information. ${ }^{1}$ During Advanced Pharmacy Practice Experiences (APPEs), students will need competency and flexibility in abbreviated documentation styles.

Timely communication is crucial since delays could result in incorrectly communicated or undocumented recommendations. ${ }^{9}$ As students are first learning, it is expected to take a significant amount of time. However, in practice settings, students must document within reasonable timeframes per practice standards often defined as the time services are provided or immediately thereafter. ${ }^{10}$ Students may be required to write many SOAP notes in the EMR during APPEs. ${ }^{11}$ Providing students a time limit within activities may provide practice for documenting efficiently. Although there is literature assessing SOAP note pedagogies in pharmacy students, there is no research evaluating alternative formats, such as consult notes. 


\section{OBJECTIVE}

The objective was to design, implement, and assess consult note assignments for third-year pharmacy students (P3s). This study aimed to assess performance, time to completion, and self-confidence.

\section{METHODS}

This innovative pedagogy was conducted during the third-year of a four-year curriculum as approved by the University's Institutional Review Board. Consult note writing assignments were incorporated into a Skills Laboratory course by converting existing SOAP note assignments to consult notes in the fall 2020 semester. Assignments were written and reviewed by the same faculty team to keep content expectations consistent.

Consult note assignments were completed throughout the semester (Table 1) and topics mirrored concurrent topics in pharmacotherapy (psychiatry and neurology). During the first week, a guidance document, writing template, and rubric were shared with students during a 30-minute overview lecture. Writing template available as Appendix 1 and authors will share all other materials upon request. During week 2, wrote a practice consult note in 30-minutes. Week 3 included a recitation where faculty reviewed the practice case and provided tips for writing consult notes with a key posted.

During week 4, students complete the first graded consult note. The case and writing prompt were posted five days in advance providing students unlimited time at home to complete. During week 8, the second consult note was posted 1.5 days in advance allowing unlimited time at home to complete. During week 10, students completed the third consult note. Only the case was posted one day in advance. The specific writing prompt was displayed at the start of lab and students had 60 minutes to write their note. Students could access any materials including class notes and drug-information resources. During week 13, students completed the fourth consult note with only the broad topic posted in advance. During lab, the case and writing prompt were provided and students had 90 minutes to read the case and write the note with unlimited resources. For all graded notes, a faculty-developed rubric specific for the patient case was utilized. Students received global feedback through recitation sessions and individualized feedback through written comments. The grade for each note was worth $5 \%$ of the total course grade equating $20 \%$ total. The same faculty member graded all notes for consistency in scoring and comments and estimated 10 to 15 -minutes per note to grade.

To assess this intervention, individual student consult note grades and time estimated for completion were collected for each note. Notes were graded out of 50 points utilizing a standard rubric with six sections: medication order (15points), rationale (15-points), monitoring (6-points), disease state counseling (6-points), follow-up (5-points), and format (3-points). To assess self-confidence, a pre-post Qualtrics survey was conducted with the pre-survey at the start of the semester and the post-survey at the end of the semester. Surveys were developed by two researchers based on experience teaching and grading student documentation. Surveys contained questions assessing self-confidence in overall documentation, specific consult note elements, and concerns related to writing. The overall self-confidence portion included two questions to rank confidence on a scale of 1 (not at all confident) to 10 (extremely confident) on ability to: 1) write a SOAP note and 2) write a consult note. The same scale was used to rank self-confidence for each of six specific consult note elements. The concerns section asked students to rank six items on a scale of 1 (not concerned at all) to 10 (extremely concerned). The pre-survey included demographics and an estimate on how long it took to complete a SOAP note in previous semesters.

All students completed the described activities but only students who consented for their results to be analyzed and completed both surveys were included in data analysis. All data was de-identified prior to analysis. An assessment of normality was performed revealing a non-normal distribution for all data; thus, non-parametric tests were utilized. Findings were reported with median and interquartile range (IQR). To compare scores and time to completion, Friedman's tests were utilized. Post-hoc analysis was completed with Wilcoxon Signed Rank tests to determine differences between individual assignments. To assess change in self-confidence, Wilcoxon Signed Rank tests were utilized.

\section{RESULTS}

Of the 58 students enrolled, 55 (94.8\%) consented and completed both surveys, and thus were included. Baseline characteristics included average age of 25.7 years (range $21-46$ ), $61.8 \%$ female, and $34.5 \%$ with hospital experience as a pharmacy intern. When reflecting on SOAP note writing during the previous semesters, students estimated a median of 300 minutes (IQR=180-360 minutes).

Grade median percentages were: $92 \%, 88 \%, 80 \%$, and $90 \%$ for each consult note, respectively. Ranges of grades indicate no failing grades but consult note 3 was the lowest performance. For estimated completion time, students indicated a median of 75 minutes for consult note 1, 120 minutes for note 2, 60 minutes for note 3 (in-class limit of 60 minutes), and 60 minutes for note 4 (in-class limit of 90 minutes) (Table 2). 
Student self-confidence in writing consult notes increased from a median of 5 (IQR=3-7) to 9 (IQR=8-9), $p<.001$. When assessing individual components, five elements increased significantly; one item (rationale) did not increase significantly. Students' concerns for writing notes had one item reaching statistical significance ("find appropriate literature to include in notes") with the other five items not reaching significance.

\section{DISCUSSION}

Students estimated significant time for SOAP note completion in previous semesters (median=300 minutes) compared to consult note estimates this semester. For comparison, first-year medical residents reported a mean of 60 minutes (range $=30-90$ minutes) required for systems SOAP notes. ${ }^{12}$ This represent a population more advanced in their career and thus lower documentation times would be expected. Our findings indicate efficiency in documenting consults compared to SOAP notes which may be from built-in time limitations.

Student performance on consult notes indicated similar and strong performance for consult note 1, 2, and 4 with medians of $92 \%, 88 \%$, and $90 \%$. Consult note 3 had the lower scores (median of $80 \%$ ). This note was especially challenging as the first note written during lab with a time limit and required a calculation. This finding is consistent with estimated time spent on this note as the median (60 minutes) was at the time limit indicating most students utilized the full time. When comparing note 3 to note 4 , an improvement in grades was seen without a change in estimated time, suggesting students' writing skills may have actually increased. It is also possible their competency plateaued. A stagnation in performance was observed with SOAP note writing on APPE rotations ${ }^{13}$ and may suggest the need for more consistent active feedback.

Another variable to consider is utilizing of a standardized rubric with consistent grading. The present study utilized the same rubric structure for each note, assessed by the same residency-trained PharmD faculty member. Individualized feedback was provided within a 2-week timeframe utilizing electronic comments in the learning management software. Use of a standardized SOAP note grading rubric for APPE students was associated with improved performance, selfconfidence, and grading consistency. ${ }^{14}$ While preceptors often require students to write SOAP notes on rotation, many may not provide formal assessment based on a study of 128 preceptors at five pharmacy schools. ${ }^{11}$ Even when grading is performed, significant variability in required SOAP note elements is observed across pharmacy schools, ${ }^{4}$ thus a nationally standardized rubric for documentation may aid in relaying consistent expectations.

Self-confidence in documentation skills was generally high at baseline and increased significantly between the preand post-surveys, indicating student perceived benefit. For individual consult components, a significant increase was observed for all items except "rationale". This section required students to support drug-therapy recommendation with evidence and use patient-specific characteristics for each case to discuss why different medications would or would not be appropriate. These application-based critical thinking skills tend to fully develop during clinical rotations when students gain more direct patient care exposure rather than the academic setting where this knowledge is more theoretical.

The self-confidence improvements were not necessarily driven by an increase in median score but rather the IQR (eg, "medication order" and "follow-up" sections). The practical significance of these statistically-relevant findings can be best approximated by the increased speed at which students completed note 4 without compromising academic performance. Interestingly, when comparing student overall confidence for SOAP writing to consult writing, students were more confident with SOAP notes prior to the beginning of the semester; however, at the end of the semester, consult writing overall confidence exceeded SOAP note confidence. This suggests a dedicated module for consult notes is effective. Further considerations could improve the activity such as incorporating an interactive, application-based format ${ }^{15}$ or grading a sample note. ${ }^{16}$

Previous research supports SOAP notes as a pedagogy to improve patient care skills. ${ }^{17}$ Pharmacy students believe SOAP note writing is valuable for future practice, ${ }^{18}$ but they prefer other formats, such as situation-backgroundassessment-recommendation due to perception that the latter are realistic. ${ }^{19}$ Documentation skills are relevant to postgraduate positions as $42 \%$ of residency programs included "development of a SOAP note care plan" as part of interview processes. ${ }^{20}$ There may be benefit to teaching both comprehensive and abbreviated notes.

The generalizability of these findings is limited due to a single institution with a small cohort of participants. The surveys were not psychometrically validated and involved self-assessment of students' confidence which may not indicate actual performance. It is also difficulty to draw conclusions on relative efficacy of teaching pedagogies for SOAP and consult notes as there were no head-to-head comparisons and the time measured to complete SOAP notes in previous semesters was retrospective. This proof-of-concept study did not measure long-term benefits, though a future direction could assess APPE performance.

\section{CONCLUSION}


The consult note writing assignments were successful in teaching students to document patient care in a succinct format with consideration for time efficiency. Grades demonstrated minimum competency and the decrease in time throughout the semester indicated efficiently when given time limitations. Further work should evaluate best practices for teaching documentation skills and assess the impact on APPE performance.

\section{ACKNOWLEDGEMENTS}

The authors would like to acknowledge Dr. Sun Lee for statistical support.

\section{REFERENCES}

1. Zierler-Brown S, Brown TR, Chen D, Blackburn RW. Clinical documentation for patient care: models, concepts, and liability considerations for pharmacists. Am J Health Syst Pharm. 2007;64:1851-1858. doi:

10.2146/ajhp060682.

2. Cooley J, Lee J. Implementing the pharmacists' patient care process at a public pharmacy school. Am J Pharm Educ. 2018;82(2):6301. doi: 10.5688/ajpe6301.

3. Joint Commission of Pharmacy Practitioners. Pharmacists' patient care process. https://jcpp.net/wpcontent/uploads/2016/03/PatientCareProcess-with-supporting-organizations.pdf. Accessed June 10, 2021.

4. Sando KR, Skoy E, Bradley C, Frenzel J, Kirwin J, Urteaga E. Assessment of SOAP note evaluation tools in colleges and schools of pharmacy. Curr Pharm Teach Learn. 2017;9:576-584. doi: 10.1016/j.cpt1.2017.03.010.

5. Venkat KK. Short and sweet: writing better consult notes in the era of the electronic medical record. Cleve Clin J Med. 2015;82:13-17. doi: 10.3949/ccjm.82a.14008.

6. Makam AN, Lanham HJ, Batchelor K, et al. Use and satisfaction with key functions of a common commercial electronic health record: a survey of primary care providers. BMC Medical Informatics and Decision Making. 2013;13:86. doi: 10.1186/1472-6947-13-86.

7. Kahn D, Stewart E, Duncan M, et al. A prescription for note bloat: an effective progress note template. $J$ Hosp Med. 2018;13(6):378-382. doi: 10.12788/jhm.2898.

8. Deeds S, Carr S, Garrison M, Fainstad T. Delivery of standardized patient instructions in the after-visit summary reduces telephone calls between clinic Visits. Am J Med Qual. 2018;33(6):642-648. doi: $10.1177 / 1062860618770043$.

9. American Society of Hospital Pharmacists. ASHP guidelines on documenting pharmaceutical care in patient medical records. Am J Health Syst Pharm. 2003;60(7):705-707. doi:10.1093/ajhp/60.7.705.

10. Medicare Claims Processing Manual 2021. https://www.cms.gov/Regulations-andGuidance/Guidance/Manuals/Downloads/clm104c12.pdf. Accessed June 11, 2021.

11. Lisenby KM, Andrus MR, Jackson CW, et al. Ambulatory care preceptors' perceptions on SOAP note writing in advanced pharmacy practice experiences (APPEs). Curr Pharm Teach Learn. 2018;10:1574-1578. doi: 10.1016/j.cptl.2018.09.002.

12. Mitsuishi F, Young JQ, Leary M, Dilley J, Mangurian C. The systems SOAP note: a systems learning tool. Acad Psychiatry. 2016;40(1):164-171. doi: 10.1007/s40596-014-0128-5.

13. Nguyen T, Wong E, Wang Z, Goldberg T. SOAP notes during APPEs: assessment of student performance. $J$ Pharm Pract. 2021;34(4):665-668. doi: 10.1177/0897190019885274.

14. Andrus MR, McDonough SLK, Kelley KW, et al. Development and validation of a rubric to evaluate diabetes SOAP note writing in APPE. Am J Pharm Educ. 2018;82(9):6725. doi: 10.5688/ajpe6725.

15. Alvarez EE, Reinhart JM. Use of an interactive online teaching module improved students' ability to write a clinically appropriate SOAP Note. J Vet Med Educ. 2020;47(6):700-708. doi: 10.3138/jvme.0918-107r.

16. Lee J, Thomas SA, Cates DW, McGraw-Senat CM. Improved learning experience with modified case studies courses in a pharmacy curriculum. Curr Pharm Teach Learn. 2020;12:1224-1238. doi: 10.1016/j.cptl.2020.05.005.

17. Sherman JJ, Johnson CD. Assessment of pharmacy students' patient care skills using case scenarios with a SOAP note grading rubric and standardized patient feedback. Curr Pharm Teach Learn. 2019;11:513-521. doi: 10.1016/j.cptl.2019.02.012.

18. Chan A, Lee JY, Han Z. Perception of electronic peer review of SOAP notes among pharmacy students enrolling in their first pharmacotherapeutics course. Curr Pharm Teach Learn. 2019;11:1259-1264. doi:

10.1016/j.cptl.2019.09.005. 
19. Barnett S, Nagy MW, Hakim RC. Integration and assessment of the situation-background-assessmentrecommendation framework into a pharmacotherapy skills laboratory for interprofessional communication and documentation. Curr Pharm Teach Learn. 2017;9:794-801. doi: 10.1016/j.cpt1.2017.05.023.

20. Eudaley ST, Mihm AE, Hammond DA, Szwak J, Swanson JM. Characterization of clinical knowledge and problem-solving assessments employed in postgraduate year 1 pharmacy residency interviews. Am J Health Syst Pharm. 2020;77:797-804. doi: 10.1093/ajhp/zxaa062.

Table 1. Study Design and Pedagogical Approach to Teach and Assess Consult Note Writing

\begin{tabular}{|c|c|c|}
\hline Tim & Dura & Description \\
\hline $\begin{array}{l}\text { Week 1: Consult Note } \\
\text { İntroduction }\end{array}$ & $30 \mathrm{~min}$ & $\begin{array}{l}\text { - During lab, a brief lecture was completed which covered rationale, structure, } \\
\text { comparison with SOAP notes. }\end{array}$ \\
\hline ẫ 2 : Pre-Survey & $15 \mathrm{~min}$ & $\begin{array}{l}\text { - Students complete the pre-survey as a homework assignment to assess } \\
\text { baseline confidence }\end{array}$ \\
\hline $\begin{array}{l}\text { क्षेण Veek 2: Consult Note } \\
\text { בृn-Class Practice }\end{array}$ & $30 \mathrm{~min}$ & $\begin{array}{l}\text { During lab, students spent time writing a consult note for a patient case on } \\
\text { anxiety disorders. If students did not have enough time to finish during lab, } \\
\text { they were instructed to finish at home prior to week } 3 \text {. }\end{array}$ \\
\hline 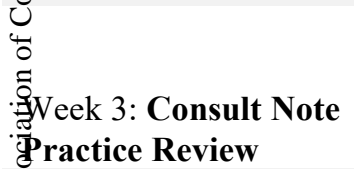 & $30 \mathrm{~min}$ & $\begin{array}{l}\text { During lab, a recitation session was conducted to review answers to the } \\
\text { practice consult note case on anxiety disorders. A key was provided so } \\
\text { students understood the ideal pharmacotherapy approach and future grading } \\
\text { method. }\end{array}$ \\
\hline 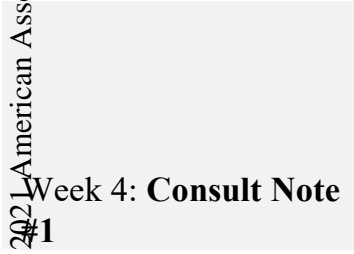 & $\begin{array}{l}\text { Unlimited time } \\
\text { provided at } \\
\text { home } \\
\quad 45 \text { min } \\
\text { recitation }\end{array}$ & $\begin{array}{l}\text { Prior to lab, the consult note case and prompt was posted } 5 \text { days in advance. } \\
\text { Students had unlimited time at home to write a consult note for a patient case } \\
\text { on schizophrenia. } \\
\text { During lab, a recitation session was conducted to review best approaches to } \\
\text { consult note \#1. } \\
\text { - This assignment was graded and was worth } 50 \text { points. }\end{array}$ \\
\hline 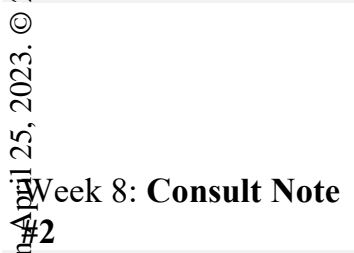 & $\begin{array}{l}\text { Unlimited time } \\
\text { provided at } \\
\text { home } \\
\quad 45 \text { min } \\
\text { recitation }\end{array}$ & $\begin{array}{l}\text { Prior to lab, the consult note case and prompt was posted } 1.5 \text { days in advance. } \\
\text { Students had unlimited time at home to write a consult note for a patient case } \\
\text { on epilepsy } \\
\text { - During lab, a recitation session was conducted to review best approaches to } \\
\text { consult note \#2. } \\
\text { This assignment was graded and was worth } 50 \text { points. }\end{array}$ \\
\hline 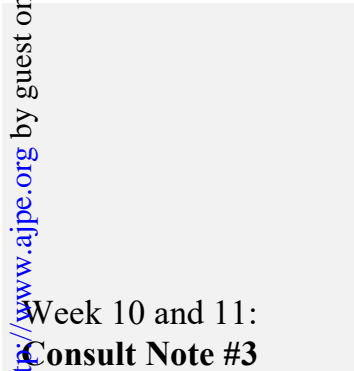 & $\begin{array}{l}60 \text { min to } \\
\text { complete } \\
\text { consult note } \\
\text { during lab } \\
15 \text { min } \\
\text { recitation (the } \\
\text { following } \\
\text { week) }\end{array}$ & $\begin{array}{l}\text { - Prior to lab, the consult note case was posted } 1 \text { day in advance. The specific } \\
\text { prompt was not posted. Students were advised to study pain management and } \\
\text { to bring resources to write a consult note on pain management including class } \\
\text { slides and pharmacotherapy guidelines. } \\
\text { - During lab, } 60 \text { minutes were provided for students to construct their consult } \\
\text { note. Students were able to use any resource, including the internet. } \\
\text { - The assignment was graded and was worth } 50 \text { points. } \\
\text { - An abbreviated recitation session was conducted the following week to review } \\
\text { best approaches to consult note } \# 3 \text {. }\end{array}$ \\
\hline (1) & $\begin{array}{l}90 \text { min to } \\
\text { complete } \\
\text { consult note } \\
\text { during lab } \\
15 \text { min } \\
\text { recitation (the } \\
\text { following } \\
\text { week) }\end{array}$ & $\begin{array}{l}\text { - Prior to lab, the consult note and the prompt were NOT posted. Instead, } \\
\text { students were advised to study rheumatoid arthritis and to bring resources to } \\
\text { write a consult note on rheumatoid arthritis including class slides and } \\
\text { pharmacotherapy guidelines. } \\
\text { - During lab, } 90 \text { minutes were provided for students to read the case and prompt } \\
\text { and construct their consult note. Students were able to use any resource, } \\
\text { including the internet. } \\
\text { - The assignment was graded and was worth } 50 \text { points. } \\
\text { - An abbreviated recitation session was conducted the following week to review } \\
\text { best approaches to consult note } \# 4 \text {. }\end{array}$ \\
\hline Week 15: Post-Survey & $15 \mathrm{~min}$ & $\begin{array}{l}\text { - Students complete the post-survey as a homework assignment to assess } \\
\text { confidence after the educational intervention }\end{array}$ \\
\hline
\end{tabular}

${ }^{a}$ Weeks not represented in this timeline did not have specific activities related to clinical documentation through consult notes. 
Table 2. Consult Note Grades and Estimated Time to Completion

\begin{tabular}{|c|c|c|c|c|c|}
\hline 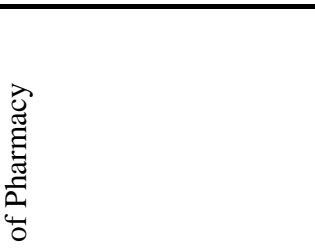 & $\begin{array}{c}\text { Consult Note } 1 \\
\text { (time unlimited) } \\
\text { Median (IQR) } \\
\text { Schizophrenia }^{\mathrm{a}}\end{array}$ & $\begin{array}{c}\text { Consult Note } 2 \\
\text { (time unlimited) } \\
\text { Median (IQR) } \\
\text { Epilepsy }^{\mathrm{a}}\end{array}$ & $\begin{array}{c}\text { Consult Note } 3 \\
\text { (time limited to } \\
60 \text { min) } \\
\text { Median (IQR) } \\
\text { Pain } \\
\text { management }^{\mathrm{a}}\end{array}$ & $\begin{array}{c}\text { Consult Note } 4 \\
\text { (time limited to } \\
90 \text { min) } \\
\text { Median (IQR) } \\
\text { Rheumatoid } \\
\text { Arthritis }\end{array}$ & $p$ value $^{\mathrm{b}}$ \\
\hline $\begin{array}{l}\text { Eonsult Note Grade } \\
\text { \&ercentage } \\
\text { \&stimated Time to } \\
\text { Exomplete in Minutes }\end{array}$ & $\begin{array}{l}92(90-96) \\
75(45-90)\end{array}$ & $\begin{array}{c}88(84-94) \\
120(60-160)\end{array}$ & $\begin{array}{l}80(72-86) \\
60(46-60)\end{array}$ & $\begin{array}{l}90(86-94) \\
60(55-65)\end{array}$ & $\begin{array}{l}<.001^{\mathrm{c}} \\
<.001^{\mathrm{d}}\end{array}$ \\
\hline
\end{tabular}

Consult note topics mirrored topics covered in the concurrent pharmacotherapy course

.

Post-hoc analysis using Wilcoxon Signed Ranked Test revealed a significant difference $(\mathrm{p}<0.05)$ between all grade comparisons with the Exception of the comparison between consult note 2 and consult note $4(\mathrm{p}=0.548)$.

త్ 

त्र

ते Table 3. Student Self-Confidence and Concerns in Writing Clinical Documentation in Pre- and Post- Surveys

\begin{tabular}{|c|c|c|c|c|}
\hline 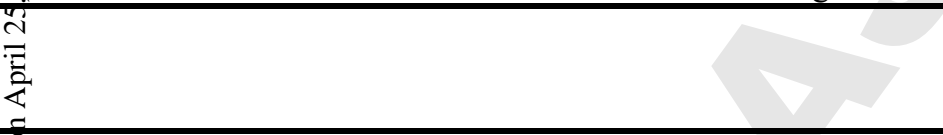 & $\begin{array}{c}\text { Pre-Survey } \\
\text { Median } \\
\text { (IQR) } \\
\end{array}$ & $\begin{array}{c}\text { Post-Survey } \\
\text { Median } \\
\text { (IQR) } \\
\end{array}$ & Change & $p$ value $^{\mathrm{c}}$ \\
\hline \multicolumn{5}{|l|}{ Survey Item Assessing Writing Confidence ${ }^{\mathrm{a}}$} \\
\hline Dverall SOAP Note Writing Confidence & $7(7-8)$ & $7(5-8)$ & 0 & .14 \\
\hline Overall Consult Note Writing Confidence & $5(3-7)$ & $9(8-9)$ & +4 & $<.001$ \\
\hline to Medication order & $8(5-9)$ & $8(7-9)$ & 0 & .04 \\
\hline ¿ Rationale & $7(5-8)$ & $7(6-8)$ & 0 & .09 \\
\hline ํㅝㄹ Monitoring for efficacy & $6(5-8)$ & $8(7-9)$ & +2 & .001 \\
\hline Monitoring for safety & $7(5-8)$ & $8(7-9)$ & +1 & .001 \\
\hline Counseling & $7(6-8)$ & $8(7-9)$ & +1 & .02 \\
\hline Follow-up & $8(6-9)$ & $8(7-9)$ & 0 & .02 \\
\hline \multicolumn{5}{|l|}{ Survey Item Assessing Concerns ${ }^{b}$} \\
\hline \multicolumn{5}{|l|}{ Find Appropriate Literature to Include in Notes (eg, primary } \\
\hline titerature, guidelines) & $5(3-8)$ & $3(2-6)$ & -2 & .03 \\
\hline INVrite the Note in a Short Period of Time (eg, 30-45 minutes) & $7(4-8)$ & $5(4-8)$ & -2 & .20 \\
\hline Present Important Information in a Clear and Concise Manner & $5(3-7)$ & $4(2-7)$ & -1 & .46 \\
\hline Adjust to Different Formats/Templates (eg, EMR dot phrases) & $5(3-7)$ & $5(3-7)$ & 0 & .97 \\
\hline Meet Deadlines Requested by Preceptor for Note Completion & $6(2-8)$ & $4(2-7)$ & -2 & .08 \\
\hline \multicolumn{5}{|l|}{ Feel Confident in Knowledge of the Disease State and Associated } \\
\hline Pharmacotherapy & $5(4-7)$ & $4(3-7)$ & -1 & .10 \\
\hline
\end{tabular}

a Each characteristic was self-assessed on a scale of 1-10 with 1 "not at all confident" and 10 "extremely confident"

b Each characteristic was self-assessed on a scale of 1-10 with 1 "not concerned at all" and 10 "extremely concerned"

${ }^{\mathrm{c}}$ Wilcoxon Signed Rank test used to compare medians

$\mathrm{APPE}=$ advanced pharmacy practice experience; $\mathrm{IQR}=$ interquartile range; $\mathrm{EMR}=$ electronic medical record 
Appendix 1. Consult Note Form

Patient Name:

Pharmacy Intern Name:

Date:

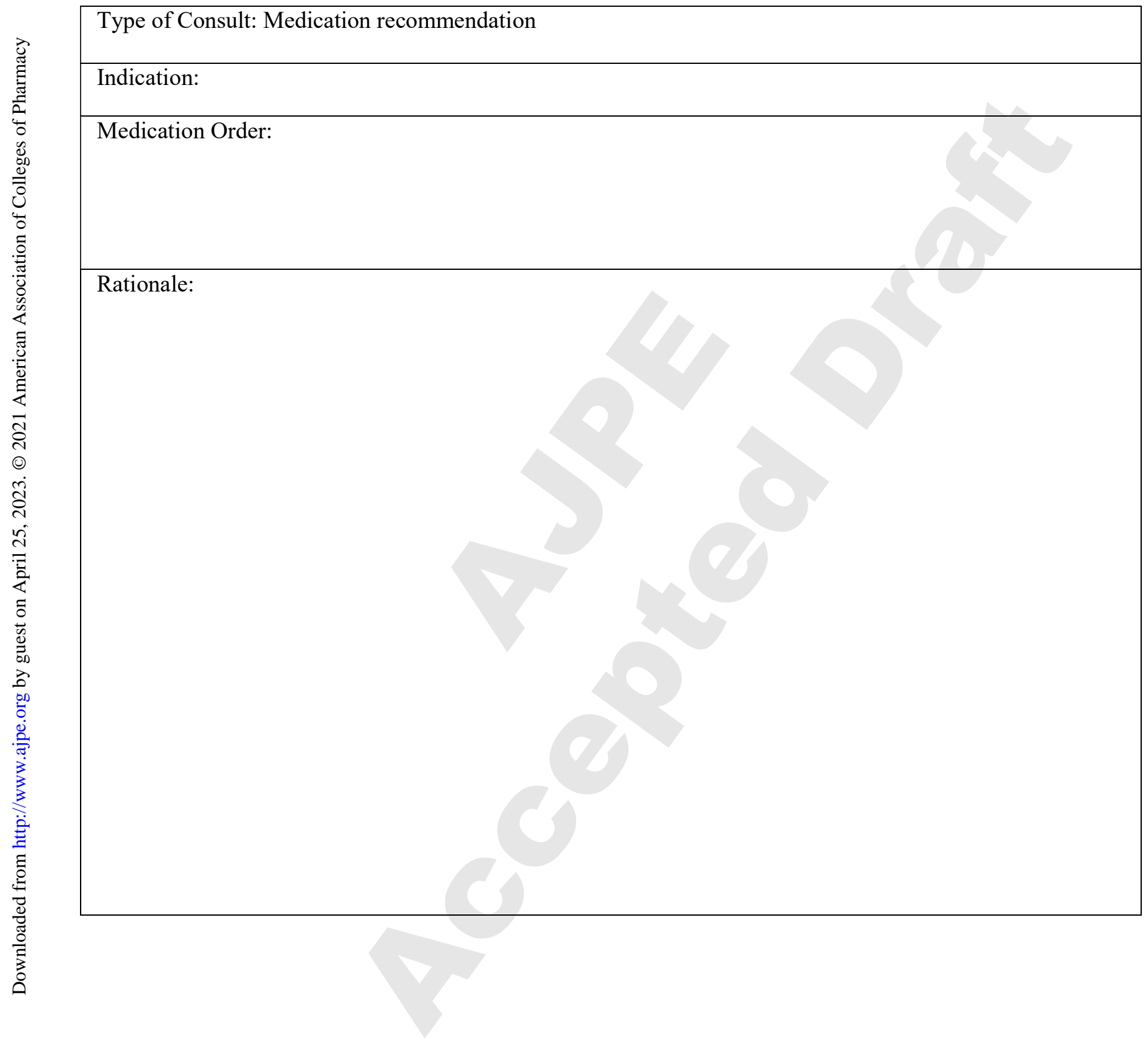




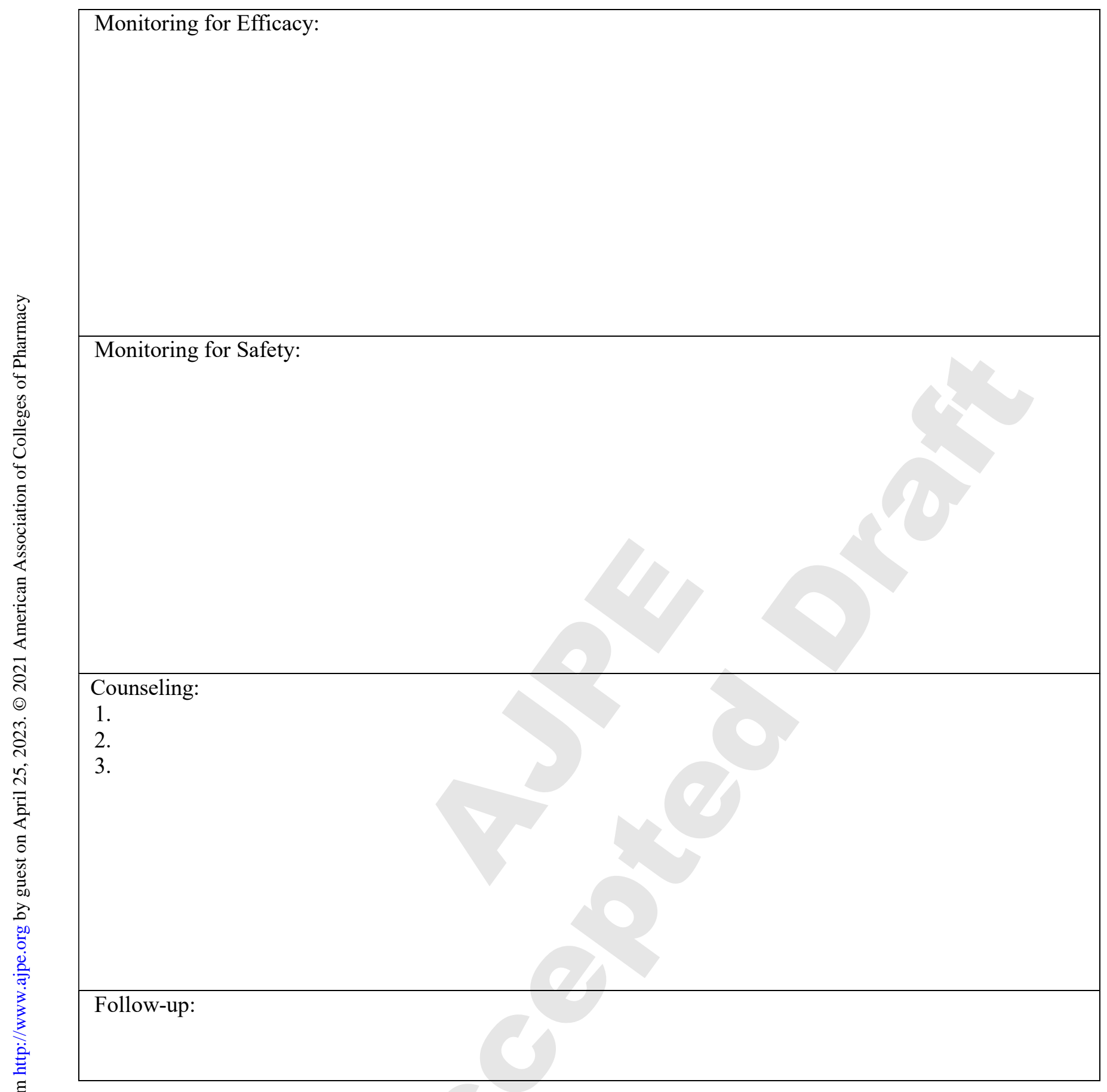

Estimated Completion Time (minutes): 